\title{
EDITORIAL
}

\section{International journal of legal medicine's manuscript submission and peer-review system goes electronic!}

\author{
Bernd Brinkmann • Heidi Pfeiffer
}

Published online: 4 April 2009

(C) Springer-Verlag 2009

We are delighted to announce that as of 1 July submitting authors and peer reviewers for the International Journal of Legal Medicine (IJLM) will be able to enjoy the comfort, speed, and transparency of "Editorial Manager," an online manuscript submission, review and tracking system. Authors will then be able to go to the Journal's homepage (http://www.springer.com/medicine/forensic/journal/414) or directly to the dedicated site at "Editorial Manager" (http:// www.edmgr.com/ijlm) and upload their papers and artwork. The entire process of peer review-submission, review, revision, decision, and all correspondence connected to itwill take place electronically.

The Journal joins almost all other Springer journals in biomedicine and life science in taking this step. As with these journals, $I J L M$ will undoubtedly also enjoy improved times to first decision and publication.

Bernd Brinkmann, Münster, Germany

Heidi Pfeiffer, Münster, Germany

Editors-in-Chief

B. Brinkmann $(\bowtie) \cdot$ H. Pfeiffer

Münster, Germany

e-mail: Brinkma@uni-muenster.de 